\title{
NÍVEL DE ALFABETIZAÇÃO FINANCEIRA DOS ESTUDANTES UNIVERSITÁRIOS: afinal, o que é relevante?
}

\section{1- Ani Caroline Grigion Potrich*}

Mestranda em Administração pelo Programa de Pós-Graduação em Administração da Universidade Federal de Santa Maria (PPGA/UFSM), Brasil.

anipotrich@gmail.com

http://lattes.cnpq.br/7790743591539041

\section{2- Kelmara Mendes Vieira}

Doutora em Administração pela Universidade Federal do Rio Grande do Sul (UFRGS), Brasil.

Professora Adjunta do Departamento de Ciências Administrativas e Pós-Graduação em Administração da Universidade Federal de Santa Maria (PPGA/UFSM), Brasil.

kelmara@terra.com.br

http://lattes.cnpq.br/4786960732238120

\section{3- Paulo Sergio Ceretta}

Doutor em Engenharia de Produção pela Universidade Federal de Santa Catarina (UFSC), Brasil.

Professor Adjunto do Departamento de Ciências Administrativas e Pós-Graduação em Administração da Universidade Federal de Santa Maria (PPGA/UFSM-RS), Brasil.

ceretta10@gmail.com

http://lattes.cnpq.br/3049029014914257

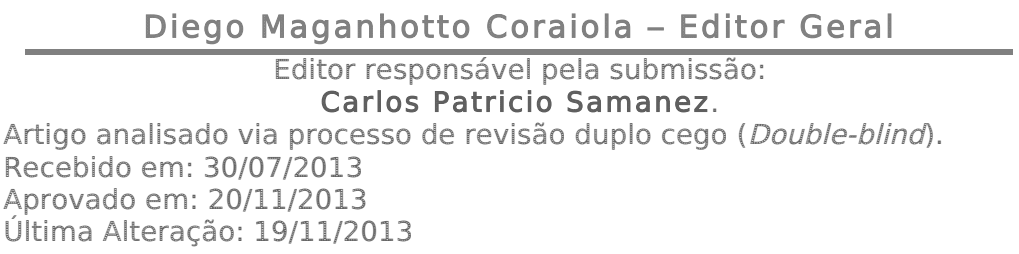

\footnotetext{
* Contato Principal: Av. Roraima no. 1000, Prédio 74 C, sala 4212, Cidade Universitária, CCSH, UFSM. Santa Maria - RS, Brasil. CEP: $97105-900$.
} 


\section{NÍVEL DE ALFABETIZAÇÃO FINANCEIRA DOS ESTUDANTES UNIVERSITÁRIOS: AFINAL, O QUE É RELEVANTE?}

\section{RESUMO}

O presente estudo teve por objetivo verificar se os estudantes universitários são alfabetizados financeiramente e se a alfabetização é afetada por variáveis socioeconômicas e demográficas. Foram aplicados questionários a 534 estudantes de graduação de universidades na região central do Rio Grande do Sul. Os resultados revelam que os estudantes apresentam um comportamento financeiro positivo, mas não satisfatório, dado que não têm, de forma bem estabelecida, hábitos de poupar mensalmente e de manter uma reserva financeira para casos inesperados. Além disso, possuem atitudes financeiras adequadas, apesar de demonstrarem um nível insatisfatório de conhecimento financeiro, culminando em um grau mediano de alfabetização financeira. Os indivíduos do gênero masculino, detentores das maiores faixas de renda e com formação financeira são os que apresentaram os níveis mais elevados de alfabetização financeira. Constatou-se, ainda, que a alfabetização financeira é influenciada positivamente pelas variáveis formação, ocupação, gênero e renda. Assim, ratifica-se a urgência e a necessidade de serem desenvolvidas ações efetivas para minimizar o problema do analfabetismo financeiro.

\section{Palavras-chave}

Alfabetização financeira; conhecimento financeiro; comportamento financeiro; atitude financeira; estudantes universitários.

\section{LEVEL OF FINANCIAL LITERACY OF COLLEGE STUDENTS: WHAT IS RELEVANT?}

\section{ABSTRACT}

The present study aimed to verify whether college students are financially literate and whether literacy is affected by socioeconomic and demographic variables. Questionnaires were applied to 534 undergraduate students from universities in the central region of Rio Grande do Sul. The results have indicated that students have a positive financial behavior, but not satisfactory. It has also been found that they do not have wellestablished habits to save monthly and to maintain a financial reserve for unexpected cases. Although they have adequate financial attitudes, they have showed an unsatisfactory level of financial knowledge, culminating in a moderate degree of financial literacy. The male individuals with higher income brackets and financial training are those with the highest levels of financial literacy. It was also found that financial literacy is positively influenced by variables such us training, occupation, gender and income. This way, the urgent need to develop effective actions to minimize the problem of financial illiteracy has been confirmed.

\section{Keywords}

Financial literacy; financial knowledge; financial behavior; financial attitude; college students. 


\section{Introdução}

A alfabetização financeira está sendo rapidamente reconhecida como uma habilidade essencial para cidadãos que necessitam operar em um cenário financeiro cada vez mais complexo. Os governos de todo o mundo estão interessados em encontrar abordagens eficazes para melhorar o nível de alfabetização financeira da população, através da criação ou do aperfeiçoando das estratégias nacionais para a educação financeira, com o objetivo de oferecer oportunidades de aprendizagem nos diferentes níveis educacionais (Atkinson \& Messy, 2012).

Além dos governos, organismos internacionais e pesquisadores dedicam-se ao tema da alfabetização financeira. A Organização para Cooperação e Desenvolvimento Econômico [ OCDE] (2009) conceitua educação financeira como um processo em que os indivíduos melhoram a sua compreensão sobre os produtos financeiros e seus conceitos e riscos, de maneira que, a partir de informação e recomendação claras, possam desenvolver habilidades e confiança necessárias para tomar decisões fundamentadas e seguras, aumentando, consequentemente, o seu bem-estar. Na mesma linha, Anderloni e Vandone (2010) definem educação financeira como uma medida preventiva, que permite que os indivíduos tenham condições de entender problemas financeiros e gerenciar suas finanças pessoais de forma satisfatória, evitando o endividamento.

Já a alfabetização financeira, estreitamente relacionada à educação financeira, é definida, segundo a OCDE (2011), como uma combinação de consciência, conhecimento, habilidade, atitude e comportamento necessários para que os indivíduos tomem suas decisões financeiras e, finalmente, alcancem seu bem-estar financeiro. Nesse sentido, afirma-se que a educação financeira é um processo de desenvolvimento de habilidades que facilitam que as pessoas tomem decisões acertadas, realizando uma boa gestão de suas finanças pessoais, e que a alfabetização financeira é a capacidade de usar o conhecimento e as habilidades adquiridas. Simplificadamente, pode-se dizer que a educação financeira tem relação com o conhecimento, enquanto que a alfabetização financeira envolve, além do conhecimento, o comportamento e a atitude financeira dos indivíduos.

No entanto, ainda não há, no meio acadêmico, um consenso sobre os melhores instrumentos para mensurar educação e alfabetização financeira. Nos últimos anos, foram realizados diversos trabalhos nos EUA sobre o tema, dos quais se destacam os de Chen e Volpe (1998), Chen e Volpe (2002), Avard, Manton, English e Walker (2005), Murphy e Yetmar (2010) e Neidermeyer e Neidermeyer (2010). Também foram realizados estudos no Reino Unido com famílias, como o de Lusardi e Tufano (2009) e Disney e Gathergood (2011), no Japão, como o de Sekita (2011), em Gana com universitários, como o de Ansong (2011), e na da Holanda com aposentados, como o de Rooij, Lusardi e Alessie (2011). No cenário brasileiro, o assunto foi destaque nos trabalhos conduzidos por Lucci, Zerrenner, Verrone e Santos (2006), Aviz (2009), Claudino, Nunes e Silva (2009), Vieira, Bataglia, Sereia, Ribeiro e Lohmann (2009), Amadeu (2009), dentre outros.

Além da mensuração da educação e alfabetização financeira, alguns desses estudos buscam avaliar a influência do perfil profissional dos entrevistados. Chen e Volpe (1998) analisaram os conhecimentos em finanças pessoais de 942 estudantes de 13 universidades, localizadas na Califórnia, na Flórida, em Kentucky, em Massachusetts, em Ohio e na Pensilvânia, e constataram que os estudantes possuíam um nível de conhecimento inadequado, principalmente com relação a investimentos. No Reino Unido, Disney e Gathergood (2011) verificaram que as pessoas que possuem um nível maior de alfabetização financeira tendem a assumir dívidas com menores custos.

No universo brasileiro, Lucci et al. (2006) conduziram uma pesquisa na Faculdade Independente Butantã, com 122 alunos dos cursos de graduação em Administração e Ciências Contábeis, e averiguaram que o nível dos conceitos financeiros é diretamente proporcional ao nível de educação financeira. Outro estudo realizado no Brasil por Amadeu (2009) com estudantes da Universidade Estadual do Norte do Paraná buscou analisar atitudes, comportamentos e níveis de conhecimento dos iniciantes e concluintes relacionados a finanças pessoais, verificando que estes demonstraram atitudes, comportamentos e conhecimentos de finanças pessoais significativamente melhores que os estudantes do primeiro ano.

Nesse contexto, a presente pesquisa tem como objetivos principais construir uma escala de alfabetização financeira e analisar a influência das variáveis socioeconômicas e demográficas nessa escala. Uma hipótese central neste trabalho é a de que indivíduos que, durante sua formação profissional, concluíram disciplinas relativas às Finanças, como, por exemplo, Matemática, Matemática Financeira, Administração Financeira e outras, atinjam melhores desempenhos em indicadores de alfabetização financeira do que aqueles cuja educação formal não envolva tais disciplinas. Uma inovação deste trabalho é a criação de um índice de avaliação do conhecimento financeiro, o qual se divide em conhecimento básico e conhecimento avançado. Além disso, analisa, a partir de uma escala de percepção, o comportamento e as atitudes financeiras dos indivíduos.

Assim, para responder aos objetivos propostos, o trabalho está estruturado em cinco seções, incluindo esta introdução. Na segunda seção, apresenta-se a revisão de literatura, com ênfase nos tópicos definidos para o trabalho; na terceira seção, expõem-se os procedimentos metodológicos adotados; na quarta seção, encontram-se as análises e discussões dos resultados; e por último, são tecidas as considerações mais relevantes acerca do estudo realizado, bem como limitações e sugestões para pesquisas futuras. 


\section{Referencial Teórico}

\subsection{Alfabetização Financeira}

O termo alfabetização financeira, em inglês denominado Financial Literacy, tem sido frequentemente utilizado como sinônimo de educação financeira ou conhecimento financeiro. No entanto, esses dois construtos são conceitualmente diferentes e usá-los como sinônimos pode gerar problemas, uma vez que a alfabetização financeira vai além da mera educação financeira. Huston (2010) argumenta que a alfabetização financeira possui duas dimensões: o entendimento, que representa o conhecimento financeiro pessoal ou a educação financeira, e a sua utilização, ou seja, a aplicação de tais conhecimentos na gestão das finanças pessoais.

Para Hung, Parker e Yoong (2009), a educação financeira é o processo pelo qual as pessoas melhoram sua compreensão em relação a produtos, serviços e conceitos financeiros, e, com isso, fazem escolhas mais informadas, evitando armadilhas e sabendo onde obter ajuda, o que leva, a longo prazo, a um aumento do seu bem-estar financeiro. Já a alfabetização financeira é a capacidade de usar o conhecimento e as habilidades adquiridas para gerir de forma eficaz os recursos, proporcionando um bem-estar financeiro. Lusardi e Tufano (2009) definem a alfabetização financeira como a capacidade de tomar decisões simples sobre os contratos de dívida, mais especificadamente, como a aplicação dos conhecimentos básicos sobre juros compostos, no contexto cotidiano das escolhas financeiras.

Além disso, o indivíduo pode possuir conhecimento financeiro, mas, para ser considerado alfabetizado financeiramente, deve possuir a habilidade e a confiança necessárias para aplicar esse conhecimento nas suas tomadas de decisões. Nesse sentido, a alfabetização financeira vai além da ideia básica de educação financeira (Huston, 2010; Mccormeck, 2009). De acordo com Criddle (2006), possuir alfabetização financeira não é apenas saber construir orçamentos para poupança futura ou checar contas bancárias. A definição de alfabetização financeira inclui o aprendizado quanto à escolha de inúmeras alternativas para o estabelecimento dos objetivos financeiros e, além disso, uma reflexão acerca dos próprios valores do dinheiro. Nessa mesma visão, a alfabetização financeira, segundo Schagen (1997), refere-se à capacidade de fazer julgamentos informados e tomar decisões eficazes em relação ao uso e à gestão do dinheiro e, para Mandell (2007), diz respeito à capacidade de avaliar os novos e complexos instrumentos financeiros e fazer julgamentos informados, tanto na escolha desses instrumentos como na forma de uso mais adequado.

Ao realizar uma extensa revisão teórica abrangendo estudos sobre alfabetização financeira, desenvolvidos entre os anos 2000 e 2010, Remund (2010) constatou que, apesar de não haver uniformidade entre as definições propostas, a maioria das conceituações sobre o tema faz uso das seguintes categorias: conhecimento de conceitos financeiros, habilidade para comunicar conceitos financeiros, atitude para gerenciar as finanças pessoais, habilidade para tomar decisões financeiras apropriadas e confiança para planejar as necessidades financeiras futuras. Assim, tendo por base essas categorias, Remund (2010) definiu a alfabetização financeira como uma medida do grau em que um indivíduo entende conceitos financeiros chaves e possui habilidade e confiança para gerir adequadamente suas finanças pessoais, mediante a tomada de decisões de curto prazo e a realização de um planejamento financeiro de longo prazo, enquanto permanece atento aos eventos de sua vida e às mudanças das condições econômicas.

Em uma visão similar, para Hung, Parker e Yoong (2009), a alfabetização financeira pode ser elucidada por quatro variáveis: conhecimento financeiro, atitude financeira, comportamento financeiro e habilidade financeira, as quais estão correlacionadas entre si; o conhecimento financeiro coordena as atitudes, e estas, por sua vez, influenciam o comportamento de gestão financeira. Nesse mesmo contexto, Norvilitis e MacLean (2010) e Xiao, Tang, Serido e Shim (2011) ratificam que o conhecimento financeiro por si só não é suficiente para a gestão eficaz das finanças, uma vez que a influência do conhecimento financeiro sobre o comportamento é mediada pelas atitudes financeiras dos estudantes.

A alfabetização financeira, segundo Vitt (2004), desempenha um papel essencial no processo de tomada de decisões financeiras responsáveis, pois representa um esforço sistemático visando ao desenvolvimento de conhecimentos, comportamentos e atitudes financeiras positivas. Além disso, Anderloni e Vandone (2010) argumentam que uma das grandes funções da alfabetização é atuar como medida preventiva para o controle da inadimplência, uma vez que a mesma aumenta a compreensão dos indivíduos em relação às suas transações financeiras, tornando-os mais capacitados para a tomada de decisões.

\subsection{Instrumentos de Avaliação da Alfabetização Financeira}

A medição da alfabetização financeira é outra questão complexa. Lusardi e Mitchell (2011) defendem o argumento de que, embora seja importante avaliar como as pessoas são financeiramente alfabetizadas, na prática, é difícil explorar a forma como estas processam as informações financeiras e tomam suas decisões baseadas nessas informações. Huston (2010) acrescenta que seria importante determinar não apenas se a pessoa tem a informação, mas também se ela sabe aplicá-la de forma apropriada. Kempson (2011), ao realizar uma investigação acerca das pesquisas em alfabetização financeira, constatou uma grande diversidade, tanto em sua cobertura quanto na natureza das perguntas que foram feitas. Devido à dificuldade de medição da alfabetização financeira de forma direta, Moore (2003) sugere a utilização de proxies.

Encontra-se, na literatura, um conjunto de três perguntas desenvolvidas por Lusardi e Mitchell (2011), que são comumente usadas em diversos estudos. As perguntas compreendem três conceitos básicos sobre 
composição financeira: taxa de juros, inflação e diversificação de risco. A primeira questão compreende noções acerca da taxa de juros - Suponha que você tenha \$100 em uma conta de poupança e a taxa de juros é de $2 \%$ ao ano. Após 5 anos, quanto você acha que teria na conta se tivesse deixado o dinheiro guardado: 1) Mais de $\$ 102$; 2) \$102 exatamente; 3) Menos de \$102; 4) Não sabe. A segunda questão trata do entendimento da inflação - Imagine que a taxa de juros em sua conta poupança foi de $1 \%$ ao ano e a inflação foi de $2 \%$ ao ano. Após 1 ano, você seria capaz de comprar com o dinheiro desta conta: 1) Mais do que hoje; 2) Exatamente o mesmo; 3) Menos do que hoje; 4) Não sabe. A terceira questão diz respeito à compreensão da diversificação de risco - Você acha que a seguinte afirmação “A compra de uma única ação de empresa geralmente oferece um retorno mais seguro do que um estoque de fundo mútuo" é verdadeira ou falsa? 1) Verdadeira; 2) Falsa; 3) Não sabe.

Essas questões têm sido objeto de diversas pesquisas porque formam uma base útil de comparação entre países sobre alfabetização financeira. Dentre as pesquisas, destaca-se a de Lusardi e Mitchell (2011) nos EUA, Fornero e Monticone (2011) na Itália, Bucher-Koenen e Lusardi (2011) na Alemanha, Sekita (2011) no Japão, Crossan, Feslier e Hurnard (2011) na Nova Zelândia, Almenberg e Save-Soderbergh (2011) na Suécia, Alessie, Van Rooij e Lusardi (2011) na Holanda e Klapper e Panos (2011) na Rússia. Estudos adicionais usando essas perguntas foram realizados por Cole, Sampson e Zia (2009) na Indonésia e no estado de Gujurat, na Índia e por Behrman, Mitchell, Soo e Bravo (2010) no Chile. Tais pesquisas detectaram que a alfabetização financeira é baixa em todos esses países, embora seja ainda menor nos países de baixa renda. Lusardi e Mitchell (2011) observaram nos EUA que apenas cerca de $65 \%$ dos entrevistados responderam corretamente à primeira ou à segunda pergunta, enquanto que apenas metade acertou a terceira pergunta. Já Sekita (2011) detectou um desempenho pior no teste de alfabetização financeira para as pessoas no Japão, já que a taxa de acerto foi de $50 \%$ nas duas primeiras perguntas e de $40 \%$ na última pergunta.

Diante disso e do pedido de muitos países para criação de uma medida robusta de alfabetização financeira, a nível nacional, a Organização para Cooperação e Desenvolvimento Econômico (OCDE, 2011) criou a Rede Internacional de Educação Financeira (INFE) a fim de facilitar a partilha de experiências e conhecimentos entre especialistas e o público em todo o mundo, além de promover o desenvolvimento dos trabalhos de análise e de recomendações políticas, estabelecendo um instrumento de pesquisa que pode ser usado para averiguar a alfabetização financeira de pessoas em diversos países. De posse desse instrumento, em 2012, realizou um estudo piloto em 14 países de quatro continentes. O questionário da OECD centra-se nos aspectos de conhecimentos, atitudes e comportamentos que estão associados com os conceitos globais de alfabetização financeira. Os resultados do teste destacam a falta de conhecimento financeiro em uma proporção considerável da população de cada um dos países pesquisados. Além disso, há espaço para melhorias em termos de comportamento financeiro e as atitudes variaram substancialmente. No que se refere ao gênero, na maioria dos países, as mulheres pesquisadas possuem menos conhecimento financeiro do que os entrevistados do gênero masculino.

Além desses instrumentos, alguns autores avaliam as dimensões da alfabetização financeira separadamente, como é o caso de Rooij, Lusardi e Alessie (2011), que examinaram a relação entre o conhecimento financeiro e o planejamento da aposentadoria na Holanda. Cita-se, também, o estudo do brasileiro Matta (2007), que criou uma escala composta por 20 questões a fim de avaliar o comportamento referente aos aspectos de gestão financeira, crédito pessoal, consumo e investimento e poupança. Outra medida utilizada em algumas pesquisas é o Instrumento FL-ABK (Financial Literacy - Attitude, Behavior and Knowledge), elaborado pela pesquisadora Susan Smith Shockey (2002), na sua tese de doutorado em filosofia pela Universidade do Estado de Ohio nos Estados Unidos, quando utilizou a escala tipo Likert para analisar as atitudes e os comportamentos dos respondentes.

Apesar da existência de tantos instrumentos, Marcolin e Abraham (2006) destacam a possibilidade de que alguns aspectos da alfabetização financeira sejam mais ou menos significantes, no sentido econômico, para determinar o bom ou mau comportamento financeiro e, consequentemente, determinar o menor ou maior grau de sucesso, sugerindo estudos com componentes específicos da alfabetização financeira que, combinados com certas características demográficas, teriam maior influência na obtenção do sucesso financeiro.

\subsection{Relação das Variáveis Socioeconômicas e Demográficas com a Alfabetização Financeira}

Em uma pesquisa realizada com alunos de graduação, Shim, Barber, Card, Xiao e Serido (2010) verificaram que, enquanto alguns estudantes buscavam aprender a gerenciar melhor suas finanças, outros adotavam comportamentos de risco, extrapolando o valor de seu orçamento, contraindo dívidas excessivas no cartão de crédito e deixando de cumprir com os compromissos financeiros dentro do prazo. Para Shim et al. (2010), o melhor entendimento do motivo para a ocorrência dessa disparidade de comportamento pode ser obtido mediante a análise do perfil socioeconômico e demográfico dos estudantes, tendo em a influência de tais fatores sobre a alfabetização financeira.

Lusardi e Mitchell (2011) constataram que as mulheres nos EUA são significativamente menos propensas a responder às perguntas corretamente e mais propensas a dizer que elas não sabem a resposta. Por outro lado, as mulheres também avaliam seu próprio nível de alfabetização financeira de forma mais conservadora, sendo tal fato verdadeiro em quase todos os países, tanto nos desenvolvidos como nos em desenvolvimento. Estudos realizados por Chen e Volpe (1998) e Lusardi e Mitchel (2010) ampliam as evidências de que as 
mulheres apresentam maior dificuldade em realizar cálculos financeiros e menor nível de conhecimento financeiro, o que acaba por dificultar a habilidade da tomada de decisões financeiras responsáveis. Uma exceção é evidencia encontrada por Bucher-Koenen e Lusardi (2011) de que não há diferenças entre os comportamentos de ambos os gêneros na Alemanha Oriental.

\begin{tabular}{|c|c|c|}
\hline Variáveis & Relação com a alfabetização financeira & Autores \\
\hline Gênero & $\begin{array}{c}\text { - As mulheres geralmente apresentam menores índices de } \\
\text { alfabetização financeira do que os homens; } \\
\text { - As mulheres são menos propensas a responder às perguntas } \\
\text { corretamente e mais propensas a dizer que não sabem a } \\
\text { resposta; } \\
\text { - A educação financeira dos homens está aumentando mais } \\
\text { rapidamente do que a das mulheres; } \\
\text { - Fazendo um comparativo entre mulheres, aquelas casadas e } \\
\text { com renda mais alta possuem melhores níveis de alfabetização } \\
\text { financeira. }\end{array}$ & $\begin{array}{l}\text { Chen e Volpe (1998); } \\
\text { Lusardi e Mitchell (2005); } \\
\text { Lusardi e Mitchell (2011); } \\
\text { Atkinson e Messy (2012); } \\
\text { Agarwalla et al. (2012). }\end{array}$ \\
\hline Idade & $\begin{array}{c}\text { - A idade média de } 30 \text { a } 40 \text { anos está associada com os maiores } \\
\text { índices de educação financeira; } \\
\text { - A educação financeira é mais baixa entre os mais jovens e } \\
\text { mais velhos. }\end{array}$ & $\begin{array}{l}\text { Lusardi e Tufano (2009); } \\
\text { Lusardi e Mitchell (2011); } \\
\quad \text { Finke et al. (2011); } \\
\text { Atkinson e Messy (2012). }\end{array}$ \\
\hline Estado civil & $\begin{array}{l}\text { - Os solteiros são significativamente mais propensos a ter } \\
\text { menores conhecimentos financeiros do que os casados. }\end{array}$ & Research (2003). \\
\hline Escolaridade & $\begin{array}{c}\text { - Aqueles com maiores níveis de alfabetização financeira são os } \\
\text { que possuem maiores níveis de escolaridade; } \\
\text { - O número de disciplinas ligadas à área financeira cursadas na } \\
\text { graduação está relacionado ao nível de educação financeira; } \\
\text { - Aqueles com menor nível educacional são menos propensos a } \\
\text { responder às perguntas corretamente e mais propensos a dizer } \\
\text { que não sabem a resposta. }\end{array}$ & $\begin{array}{c}\text { Amadeu (2009); } \\
\text { Lusardi e Mitchell (2011). }\end{array}$ \\
\hline Renda & $\begin{array}{l}\text { - Baixos níveis de renda estão associados a baixos níveis de } \\
\text { alfabetização financeira; } \\
\text { - Alfabetização financeira e riqueza são conjuntamente } \\
\text { determinadas e correlacionadas ao longo do ciclo de vida. }\end{array}$ & $\begin{array}{l}\text { Lusardi e Tufano (2009); } \\
\text { Monticone (2010); } \\
\text { Jappelli e Padula (2011); } \\
\text { Hastings e Mitchell (2011); } \\
\text { Atkinson e Messy (2012). }\end{array}$ \\
\hline Trabalho & $\begin{array}{c}\text { - Indivíduos com maior tempo de serviço são mais alfabetizados } \\
\text { financeiramente em virtude da maior convivência com questões } \\
\text { econômicas e financeiras, enquanto que trabalhadores com } \\
\text { baixa qualificação ou desempregados apresentam atitudes e } \\
\text { comportamentos menos desejáveis. }\end{array}$ & $\begin{array}{l}\text { Chen e Volpe (1998); } \\
\text { Research (2003). }\end{array}$ \\
\hline Etnia & $\begin{array}{c}\text { - Estudantes brancos apresentam melhores níveis de } \\
\text { responsabilidade financeira; } \\
\text { - Negros e hispânicos são menos propensos a responder } \\
\text { corretamente questões sobre esse assunto. }\end{array}$ & $\begin{array}{l}\text { Lusardi e Mitchell (2005); } \\
\text { Grable e Joo (2006); } \\
\text { Lusardi e Mitchell (2011). }\end{array}$ \\
\hline
\end{tabular}

Figura 1: Síntese da relação entre as variáveis demográficas e socioeconômicas e a alfabetização financeira Fonte: Elaborada pelos autores.

As principais pesquisas relatam que a alfabetização financeira tende a ser maior entre os adultos e menor entre os jovens e os idosos. Os resultados do estudo de Lusardi e Mitchell (2011) demonstraram que os pesquisados na faixa etária entre 25 e 65 anos tendem a acertar $5 \%$ mais questões do que os menores de 25 anos ou maiores de 65 anos. Finke, Howe e Huston (2011) também atribuíram menor alfabetização financeira às pessoas mais velhas, devido a um declínio nos processos cognitivos associados à velhice.

As pesquisas também descobriram uma relação entre alfabetização financeira e renda. Segundo Atkinson e Messy (2012), os baixos níveis de renda estão associados com os menores níveis de alfabetização financeira, - que pode ser explicado uma vez que indivíduos de baixa renda podem enfrentar maiores dificuldades no acesso à educação. Monticone (2010) usa dados da Itália para mostrar que a riqueza tem um efeito pequeno, mas positivo sobre a alfabetização financeira. Behrman et al. (2010) utilizam uma análise de regressão de variáveis instrumentais para demonstrar que a alfabetização financeira também tem um efeito causal sobre a acumulação de riqueza nos EUA. Bottazzi, Jappelli e Padula (2011) estimaram um modelo intertemporal de investimento em educação financeira, evidenciando que a alfabetização financeira e a riqueza são conjuntamente determinadas e correlacionadas ao longo do ciclo de vida dos indivíduos. Enquanto isso, Hastings e Mitchell (2011) fornecem evidências experimentais do Chile para mostrar que a alfabetização financeira está relacionada à riqueza.

Outra variável sociodemográfica relacionada à alfabetização financeira é o nível de escolaridade. Maiores níveis de alfabetização financeira são encontrados em indivíduos com maior nível de escolaridade e maior acesso às informações financeiras. Nesse sentido, Amadeu (2009), em estudo realizado com 587 estudantes universitários brasileiros, aponta que o maior contato, durante a graduação ou cursos de especialização, com disciplinas de cunho financeiro ou econômico influencia positivamente as práticas financeiras cotidianas, tendo sido encontrado nos alunos dos cursos de Ciências Econômicas e Administração os maiores níveis de conhecimento financeiro. Corroborando com tal evidência, Lusardi e Mitchell (2011) concluíram que os indivíduos com menor nível educacional nos EUA são menos propensos a responder às perguntas corretamente e mais propensos a dizer que não sabem a resposta. 
O estado civil e a experiência profissional também apresentam relação com o grau de alfabetização financeira. De acordo com Research (2003), os solteiros são significativamente mais predispostos a ter menores níveis de conhecimento financeiro se comparados aos indivíduos casados. Chen e Volpe (1998), após pesquisa realizada com estudantes universitários, concluíram que indivíduos com maior tempo de serviço passam por mais experiências financeiras e, por esse motivo, adquirem maiores conhecimentos, facilitando, assim, a análise de informações mais complexas e a tomada de decisão. Por outro lado, segundo Research (2003), trabalhadores com baixa qualificação ou desempregados tendem a apresentar desempenho inferior devido ao menor contato com questões financeiras. O regime de trabalho também pode influenciar as atitudes e os comportamentos financeiros, tendo em vista que indivíduos com renda estável possuem melhores condições de organizar e planejar sua vida financeira.

Outro fator impactante na alfabetização financeira são as disparidades de etnia e raça. Entre os países de maior renda, Lusardi e Mitchell (2011) encontraram pontuações de alfabetização financeira nos EUA mais baixas entre os hispânicos e negros do que entre os brancos e asiáticos. Já Grable e Joo (2006), ao estudarem a educação financeira, concluíram que os estudantes universitários que se autointitulam brancos apresentam melhores níveis de responsabilidade financeira em comparação com os estudantes universitários negros.

Portanto, os estudos indicam uma associação entre os níveis de alfabetização financeira e as variáveis socioeconômicas e demográficas. Assim, tais aspectos devem ser avaliados nas definições das estratégias de países que buscam oferecer alfabetização financeira de forma eficiente. A Figura 1 apresenta uma síntese das relações observadas na literatura entre as variáveis demográficas e socioeconômicas e a alfabetização financeira.

\section{Procedimentos Metodológicos}

Participaram deste estudo 534 estudantes de diferentes semestres e cursos de universidades públicas e privadas da cidade de Santa Maria, Rio Grande do Sul. A coleta dos dados foi realizada de forma aleatória, em ambiente interno, através da disponibilidade dos professores e do contato com os estudantes dispostos a participar da pesquisa. O instrumento de coleta de dados foi aplicado durante os meses de abril e maio de 2013 e foi composto por quatro blocos de perguntas. Inicialmente, buscou-se identificar o perfil dos respondentes por meio de oito questões relacionadas a variáveis socioeconômicas e demográficas: gênero, idade, estado civil, dependentes, raça, ascendência, ocupação e renda.

Tendo em vista que não há um instrumento operacional validado que mensure a alfabetização financeira em sua totalidade (Remund, 2010), optou-se pela utilização de uma proxy, seguindo o procedimento adotado por diversos pesquisadores (Aktinson \& Messy, 2012; Shim, Xiao, Barber \& Lyons, 2009; Shim et al., 2010; Knoll \& Houts, 2012), os quais têm, normalmente, avaliado a alfabetização através de fatores. Nesse estudo, a alfabetização financeira é formada pelos seguintes fatores: conhecimento financeiro, comportamento financeiro e atitude financeira. Uma vez que os maiores níveis de conhecimento financeiro são encontrados em indivíduos com maior nível de escolaridade e maior acesso às informações financeiras, como demonstra o estudo realizado por Lusardi e Mitchell (2005), ao concluíram que os indivíduos com menor nível educacional nos EUA são menos propensos a responder às perguntas corretamente e mais propensos a dizer que não sabem a resposta, optouse por realizar a pesquisa com estudantes universitários, que, em síntese, apresentam tal realidade.

A fim de mensurar o comportamento financeiro, foi utilizada a medida proposta por Matta (2007), que foi desenvolvida com base nos estudos de Chen e Volpe (1998), Johnson (2001) e Shockey (2002). A medida, composta por 20 questões, está organizada em uma escala do tipo likert de 5 pontos (em que $1=$ nunca e $5=$ sempre) e avalia o comportamento mantido pelos estudantes universitários em relação à gestão financeira, à utilização do crédito pessoal, ao consumo planejado, ao investimento e à poupança. O fator comportamento financeiro foi composto, assim, pela média das 20 questões, o que quer dizer que, para cada entrevistado, foi computada a média das respostas atribuídas a cada questão da escala.

Para avaliar o nível de conhecimento financeiro dos acadêmicos, foi construído um fator a partir da média da pontuação de dois conjuntos de questões de múltipla escolha adaptadas de Rooij, Lusardi e Alessie (2011). O primeiro conjunto (conhecimento básico), composto por três perguntas, visou medir habilidades financeiras básicas, como o entendimento de questões relacionadas à inflação, à taxa de juros composta e ao valor do dinheiro no tempo. O segundo grupo (conhecimento avançado), composto por cinco questões, buscou explorar o nível de conhecimento em relação a instrumentos financeiros complexos, tais como ações, títulos públicos e diversificação de risco. Dessa forma, o fator conhecimento financeiro é composto pela média da pontuação obtida nas questões de conhecimento básico e avançado. Para cada uma das três questões de conhecimento básico foi atribuído peso 1,0 para a resposta correta e para cada uma das cinco questões de conhecimento avançado foi atribuído peso 2,0. Dessa forma, o estudante que acertou as três questões de conhecimento básico atingiu uma pontuação média de 1,0 ponto, enquanto que o estudante que acertou todas as questões de conhecimento avançado atingiu pontuação média de 2,0 pontos. O índice de conhecimento financeiro variou de 0 (pontuação obtida se o estudante errar todas as questões) a 3,0 (pontuação obtida caso o estudante acerte todas as questões). De acordo com a pontuação obtida, os respondentes foram analisados como detentores de baixo nível de conhecimento financeiro (pontuação inferior a $60 \%$ ), nível médio (entre $60 \%$ e $79 \%$ da pontuação máxima) e alto nível de conhecimento (acima de $80 \%$ da pontuação máxima). Tal classificação foi estabelecida por Chen e Volpe (1998). 
Para mensurar a atitude financeira, foi empregada a escala desenvolvida por Shockey (2002). Essa escala, composta por nove questões, é do tipo likert de 5 pontos (em que $1=$ discordo totalmente e $5=$ concordo totalmente) e visa identificar como o indivíduo avalia sua gestão financeira. Assim, o fator atitude financeira foi composto pela média de todas as questões, o que significa que, para cada entrevistado, foi computada a média das respostas.

Levando em conta o fato de que a alfabetização financeira, segundo a Organização para Cooperação e Desenvolvimento Econômico (OCDE), centra-se nos aspectos do conhecimento financeiro, da atitude financeira e do comportamento financeiro, a variável alfabetização financeira foi mensurada a partir da soma desses três aspectos, de forma padronizada. A Equação [1] resume o procedimento:

$$
\text { AlF }_{i}=\text { ComportamentoFin }_{i} / 5+\text { ConhecimentoFin }_{i} / 3+\text { AtitudeFin }_{i} / 5
$$

Em que $A l F_{i}$ é a variável alfabetização financeira; ComportamentoFin ${ }_{i} / 5$ é a média padronizada das respostas às 20 questões da escala de comportamento financeiro; ConhecimentoFin $i / 3$ é a média padronizada das respostas às oito questões da escala de conhecimento financeiro; e AtitudeFin $_{i} / 5$ é a média padronizada das respostas às nove questões da escala de atitude financeira.

Para a análise dos dados coletados, utilizaram-se estatísticas descritivas e técnicas de análise multivariada, as quais foram aplicadas através dos softwares SPSS $17.0 \AA$ e Gretl. Em um primeiro momento, foi calculada a estatística descritiva das variáveis socioeconômicas e demográficas - gênero, idade, estado civil, dependentes, raça, ascendência, ocupação e renda - visando caracterizar a amostra, e, para descrever o comportamento dos indivíduos no que tange aos fatores investigados, utilizou-se a média, a mediana e o desvio-padrão.

A fim de verificar se há diferença entre os grupos quanto aos fatores comportamento financeiro, conhecimento financeiro e atitude financeira e, posteriormente, ao fator variável alfabetização financeira, se consideradas as variáveis socioeconômicas e demográficas, foram utilizados os testes de diferença de média (teste $t$ ) e a análise de variância (ANOVA). Com o intuito de analisar as diferenças de média entre dois grupos (gênero) foi utilizado o teste $t$ de Student. Para determinar se o teste $t$ é homocedástico ou heterocedástico, foi aplicado o teste de igualdade de variâncias e, para verificar se há diferença de média para variáveis com mais de dois grupos (idade, estado civil, raça, ocupação, renda, entre outras), utilizou-se a análise de variância (ANOVA), a qual permite comparar, simultaneamente, a média de vários grupos utilizando variáveis contínuas.

Por fim, com o intuito de averiguar a influência das variáveis socioeconômicas e demográficas na alfabetização financeira, foi realizada uma análise de regressão linear múltipla, através do método dos Mínimos Quadrados Ordinários (MQO). Segundo Hair et al. (2009), a regressão linear visa analisar a relação entre uma única variável dependente, neste caso, a alfabetização financeira, com as demais variáveis independentes, que são, neste estudo, a variável idade e sete variáveis binárias: dummy gênero $(0=$ feminino e 1 = masculino), dummy estado civil ( 0 = inexistência de união estável, $1=$ existência), dummy dependentes ( 0 = ausência de dependentes, 1 = presença), dummy raça $(0$ = outras raças, $1=$ raça branca $)$, dummy ascendência $(0=$ outras ascendências, 1 = ascendência brasileira), dummy ocupação $(0=$ não trabalha, $1=$ trabalha) e dummy formação ( 0 = sem formação financeira, 1 = com formação), sendo os indivíduos com formação financeira aqueles que, durante sua formação profissional, concluíram disciplinas relativas às Finanças, como, por exemplo, Matemática, Matemática Financeira e Administração Financeira. Dessa forma, para verificar se a variável alfabetização financeira apresenta relação com as variáveis independentes, utilizou-se a Equação [ 2].

\footnotetext{
AlF $_{i}=\alpha_{0}+\beta_{1}$ Idade $_{i}+\beta_{2} D_{1}$ gênero $_{i}+\beta_{3} D_{2}$ civil $_{i}+\beta_{4} D_{3}$ dependentes $_{i}++\beta_{5} D_{4}$ raça $_{i}+\beta_{6} D_{5}$ ascendência $_{i}+\beta_{7} D_{6}$ ocupação $_{i}+$ $\beta_{8} D_{7}$ formação $_{i}+\varepsilon_{i} \quad$ [2]
}

Em que $A l F_{i}$ é a variável alfabetização financeira; $\alpha_{0}$ é o coeficiente angular da regressão; e as variáveis independentes são: Idade $_{i}$ a idade; $D_{1}$ gênero $_{i}$ a dummy gênero; $D_{2}$ civil $_{i}$ a dummy estado civil; $D_{3}$ dependentes $_{i}$ a dummy dependentes; $D_{4} r a c ̧ a_{i}$ a dummy raça; $D_{5}$ ascendência $i$ a dummy ascendência; $D_{6}$ ocupação $o_{i}$ a dummy ocupação; e $D_{7}$ formação $_{i}$ a dummy formação; e $\varepsilon_{i}$ é o coeficiente de perturbação que representa o erro.

Para verificar os pressupostos de normalidade, autocorrelação, multicolinearidade e homocedasticidade do modelo, utilizaram-se os testes de Kolmogorov-Smirnov (KS), Durbin Watson (DW), fator de inflação (FIV) e Pesarán-Pesarán, respectivamente.

Visando dar robustez à análise, o modelo proposto na Equação [2] foi reestimado de duas formas. Primeiramente, substituiu-se a variável dependente alfabetização financeira, que inicialmente foi definida conforme a Equação [1]. Uma alternativa para a montagem dessa variável é a utilização da análise fatorial exploratória. A diferença principal reside no fato de que na Equação [1] atribuem-se pesos iguais aos fatores comportamento financeiro, conhecimento financeiro e atitude financeira, enquanto que, a partir da análise fatorial exploratória, os pesos atribuídos são baseados na carga fatorial, ou seja, na contribuição do comportamento financeiro, do conhecimento financeiro e da atitude financeira para a construção do fator 
alfabetização financeira. A fim de verificar a adequação da análise fatorial para o conjunto de dados, aplicaramse os testes de esfericidade de Bartlett e a medida de Kaiser-Meyer-Olkin (KMO) e utilizou-se o método dos componentes principais. Em um segundo momento, incluiu-se na Equação [2] a variável independente Renda $\left(\beta_{9}\right.$ Rend $\left._{i}\right)$. No entanto, como alguns indivíduos não declararam renda, a amostra foi reduzida para 353 casos nesta estimação.

\section{Análise e Discussão dos Resultados}

A amostra final foi composta por 534 estudantes, dos quais 49,25\%, durante sua formação profissional, concluíram disciplinas relativas às Finanças (ou seja, possuem formação financeira) e $50,75 \%$ dos indivíduos não possuem tal formação. Os estudantes que possuem formação financeira estão cursando Administração (49\%), Ciências Contábeis (24\%), Economia (15\%), Engenharias (3\%) e Sistemas de Informação (9\%). Já os sem formação são oriundos da Pedagogia (37\%), da Psicologia (24\%), das Ciências Agrárias (19\%), do Direito (12\%), dentre outros (9\%). Quanto aos semestres cursados, $62 \%$ dos entrevistados encontram-se na fase inicial de seus cursos ( 10 ao 50 semestre) e os demais na fase final ( 60 ao 10 semestre). Verificou-se, ainda, que a maior parcela pertence ao gênero feminino $(56,93 \%)$, é solteira $(86,89 \%)$ e apresenta idade média de 24 anos, o que se justifica tendo em vista que o público-alvo da pesquisa é formado por estudantes universitários. A maior parte dos pesquisados não possui dependentes $(90,82 \%)$, considera-se pertencente à raça branca $(86,52 \%)$ e de ascendência brasileira $(49,81 \%)$. No que tange à ocupação, percebe-se que $63,67 \%$ não possuem emprego formal, sendo, em sua maioria, estudantes ou bolsistas. Mais da metade dos estudantes que declaram possuir renda apontam valores de até $\mathrm{R} \$ 1.300,00$. Após o conhecimento do perfil dos entrevistados, investigou-se seu comportamento financeiro, apresentado no Apêndice 1.

Ao analisar o comportamento financeiro dos universitários, observou-se que, em média, os participantes apresentaram um comportamento financeiro adequado, considerando que a escala varia de um (1) a cinco (5) pontos. Cabe destacar que as questões 05, 09, 11, 19 e 20, que retratam comportamentos financeiros negativos, foram invertidas de modo a serem avaliadas como as demais questões, ou seja, em uma escala ascendente, em que 1 equivale a comportamentos financeiros ruins e 5 corresponde a ótimos comportamentos financeiros. Os melhores comportamentos financeiros apresentados pelos respondentes referem-se às questões ligadas aos fatores "Consumo planejado" (média 3,994) e "Utilização de crédito" (média 3,819). Os estudantes pesquisados preocupam-se com a utilização adequada do cartão de crédito, conferindo e pagando regularmente a fatura de modo a evitar possíveis problemas financeiros. Além disso, comparam preços e analisam suas finanças antes de fazer alguma compra. O fator "Gestão financeira" apresentou média de 3,598, indicando que os estudantes apresentam relativa preocupação com o controle e o cumprimento de seus compromissos financeiros, pagando suas contas sem atraso. Já o fator "Investimento e poupança" apresentou o menor valor entre os fatores, com média de 3,157, o que revela que os universitários ainda não adquiriram o hábito de poupar mensalmente ou poupar para a aquisição de um bem de valor maior. Tal fato pode ser explicado por serem jovens e não se preocuparem com essas questões ou, ainda, por possuírem baixos rendimentos financeiros. Atkinson e Messy (2012) argumentam que as pessoas mais velhas possuem maior experiência e, portanto, conhecem a necessidade e a importância da organização e do planejamento financeiro, enquanto que os jovens, normalmente, não detêm o conhecimento e as habilidades necessárias para o gerenciamento eficiente do seu dinheiro.

Em seguida, buscou-se avaliar o nível de conhecimento financeiro dos universitários. Para tanto, foi construído um índice a partir das respostas das questões de múltipla escolha, conforme explicitado na metodologia. O Apêndice 2 apresenta a frequência de respostas corretas e incorretas e daquelas referentes às perguntas que os entrevistados não souberam responder, além do percentual de acertos. As frequências foram obtidas com base no percentual de estudantes respondentes.

O conjunto de questões do fator conhecimento financeiro básico teve por objetivo mensurar o entendimento dos universitários quanto a aspectos corriqueiros como taxa de juros, inflação e valor do dinheiro no tempo. A única questão com bom nível de acertos, acima de $60 \%$, foi a referente à inflação, o que indica que os estudantes detêm um bom conhecimento sobre esse assunto. A questão relativa à taxa de juros obteve um percentual de acertos mediano, enquanto que a questão sobre valor do dinheiro no tempo foi respondida corretamente por apenas $14,91 \%$ dos estudantes, indicando que os alunos têm dificuldade em compreender a desvalorização do dinheiro ao longo do tempo.

O segundo grupo de questões, referente ao conhecimento avançado, buscou explorar o nível de conhecimento em relação a instrumentos financeiros mais complexos, como ações, títulos públicos, diversificação de investimento, risco e retorno. Os maiores percentuais de acerto foram obtidos nas questões que abordavam peculiaridades do mercado acionário, tais como o nível de oscilação da rentabilidade das ações ao longo do tempo e a diversificação de investimentos em ativos. Por outro lado, os menores percentuais de acerto envolveram questões de fundos de investimento e retorno, mostrando que os universitários, inclusive, de áreas como Administração, Ciências Contábeis e Ciências Econômicas, que apresentam em sua grade curricular disciplinas de finanças, possuem pequeno conhecimento sobre essas questões. O conhecimento mais elevado em questões envolvendo o mercado acionário pode ser justificado pela maior facilidade de acesso a essas informações do que a informações sobre fundos de investimento. 
Assim, verificou-se o baixo nível de compreensão que os estudantes possuem em relação a assuntos que podem ser vistos e acompanhados quase que diariamente nos noticiários ou até vivenciados em situações de compra de mercadorias. Ao analisar o número de acertos por respondente, constatou-se que 5,6\% dos estudantes não acertaram ou não souberam responder nenhuma das oito questões sugeridas, $48,5 \%$ acertaram menos da metade e somente $1,3 \%$ dos estudantes acertaram todas as questões. A partir disso, buscou-se descrever o conhecimento financeiro básico e avançado e o índice de conhecimento financeiro total dos universitários (Tabela 1 ).

\begin{tabular}{|c|c|c|c|}
\hline Fator & Média & Mediana & $\begin{array}{l}\text { Desvio } \\
\text { Padrão }\end{array}$ \\
\hline Conhecimento Básico & 0,436 & 0,333 & 0,290 \\
\hline Conhecimento Avançado & 1,034 & 1,200 & 0,550 \\
\hline Índice de Conhecimento Financeiro (básico + avançado) & 1,470 & 1,533 & 0,727 \\
\hline
\end{tabular}

Tabela 1: Estatística descritiva do conhecimento financeiro básico e avançado e do índice de conhecimento financeiro

Fonte: Elaborada pelos autores.

O baixo desempenho na maioria das perguntas resultou em uma média de conhecimento financeiro básico de 0,436, considerando-se um nível máximo de 1,0 ponto, e de conhecimento avançado de 1,034, considerando-se um nível máximo de 2,0 pontos. Assim, em média, os respondentes acertaram $43,63 \%$ das questões básicas e $51,69 \%$ das avançadas. Com isso, o índice de conhecimento financeiro total apresentou uma média de 1,470 , o que significa que os respondentes acertaram apenas $49 \%$ das questões propostas, valor esse considerado muito baixo, dado o nível de escolaridade dos respondentes. Com base na classificação proposta por Chen e Volpe (1998), verificou-se que os estudantes apresentam baixo nível de conhecimento financeiro básico e avançado (abaixo de $60 \%$ de acertos), o que se mostra preocupante, na medida em que o entendimento sobre taxas de juros, inflação e valor do dinheiro no tempo é imprescindível para a realização de transações financeiras cotidianas. Porém, apresentaram um nível de conhecimento em questões avançadas superior ao das questões consideradas básicas de conhecimento financeiro.

O baixo nível de conhecimento financeiro encontrado não é exclusividade dessa pesquisa. Nos últimos anos, diferentes pesquisadores vêm se preocupando em investigar o nível de conhecimento financeiro, tanto de estudantes universitários quanto da população em geral, e vem obtendo resultados bastante preocupantes, dado os níveis insatisfatórios de conhecimento, sejam em questões de gestão financeira pessoal ou em questões mais específicas, tais como crédito, empréstimo, poupança e investimento (Disney \& Gathergood, 2010; Lusardi \& Mitchell, 2005; Lusardi \& Tuffano, 2009; Lusardi, Mitchell \& Curto, 2010; Matta, 2007; Rooij, Lusardi \& Alessie, 2011). Por exemplo, Lusardi, Mitchel e Curto (2010), em estudo realizado com 7.417 indivíduos residentes nos Estados Unidos, também observaram baixos níveis de educação financeira entre os jovens, já que apenas $27 \%$ responderam corretamente a todas as questões propostas.

Outra dimensão investigada foi a atitude financeira dos universitários, cujos resultados são apresentados no Apêndice 3. Ao analisar a atitude financeira dos universitários, constata-se que, em média, os participantes apresentaram atitudes financeiras adequadas, considerado que a escala varia de um (1) a cinco (5) pontos, em uma escala ascendente, em que 1 equivale a atitudes financeiras ruins e 5 corresponde a ótimas atitudes financeiras. As melhores atitudes financeiras referem-se às questões ligadas ao controle das despesas mensais (média 4,729) e à importância de gastar apenas o que está dentro do orçamento mensal (média 4,630). De maneira geral, todas as variáveis apresentaram bons índices de concordância, fazendo com que o fator atitude financeira apresentasse uma média de 4,429.

Após conhecer separadamente o comportamento financeiro, o conhecimento financeiro e a atitude financeira, analisou-se a variável alfabetização financeira, mensurada a partir da soma padronizada desses três fatores, em uma escala ascendente que varia de (1) a (3) pontos, conforme definido na Equação [1]. De forma geral, os universitários apresentaram um nível intermediário de alfabetização financeira, com média de 2,11 pontos, demonstrando, assim, um nível de alfabetização financeira de 70,33\%.

A partir disso, visando compreender se há diferença de média na variável criada - alfabetização financeira - e nos fatores comportamento financeiro, conhecimento financeiro e atitude financeira dos universitários, tendo em vista as variáveis demográficas e socioeconômicas, foram realizados os testes $t$ (considerando variáveis com até dois grupos) e análise de variância - ANOVA - (variáveis com mais de dois grupos). A Tabela 2 apresenta os resultados.

Para o fator comportamento financeiro, foram encontradas diferenças significativas nas variáveis gênero, raça, ocupação, formação e renda. Os entrevistados do gênero masculino demonstraram ter melhores comportamentos financeiros (média 3,75) que os do gênero feminino (média 3,61). Segundo Falahati e Paim (2012), as diferenças de comportamento entre homens e mulheres justificam-se, em parte, devido aos diferentes processos de socialização vivenciados por esses indivíduos. Enquanto as famílias adotam uma estratégia de socialização financeira mais protecionista para as mulheres, protegendo-as da prática financeira, incentivam os homens a participar da tomada de decisões financeiras, o que faz com que eles, desde cedo, adquiram um maior conhecimento e tenham uma visão mais ampla dessas questões. Considerando a raça, 
observou-se que os estudantes de raça branca (média 3,70) são mais propensos a ter melhores comportamentos financeiros do que os de outras raças (média 3,49). Ao analisar a ocupação, notou-se que os funcionários públicos (média 3,94) são os que apresentam o melhor comportamento financeiro e que os indivíduos que não possuem ocupação apresentaram os piores comportamentos (média 3,60). No que tange à formação dos estudantes, aqueles que possuem disciplinas de finanças pessoais e de mercado em sua grade curricular apresentam comportamentos financeiros mais desenvolvidos, se comparados a estudantes que não possuem tal formação, o que se justifica, em parte, pela maior conscientização acerca da importância de bons hábitos financeiros oriunda do aprendizado sobre gestão das finanças pessoais. No que diz respeito à renda, verificou-se que os universitários com maior poder aquisitivo possuem uma predisposição maior de apresentarem melhores comportamentos financeiros (média 3,88), se comparados a estudantes com nível mediano ou baixo de renda.

\begin{tabular}{|c|c|c|c|c|c|c|c|c|}
\hline \multirow[t]{2}{*}{ Variáveis } & \multicolumn{2}{|c|}{$\begin{array}{c}\text { Comportamento } \\
\text { Financeiro }\end{array}$} & \multicolumn{2}{|c|}{$\begin{array}{l}\text { Conhecimento } \\
\text { Financeiro }\end{array}$} & \multicolumn{2}{|c|}{$\begin{array}{c}\text { Atitude } \\
\text { Financeira }\end{array}$} & \multicolumn{2}{|c|}{$\begin{array}{c}\text { Alfabetização } \\
\text { Financeira }\end{array}$} \\
\hline & Valor & Sig. & Valor & Sig. & Valor & Sig. & Valor & Sig. \\
\hline Gênero (1) & 2,919 & 0,004 & 8,313 & 0,000 & $-1,680$ & 0,094 & 6,616 & 0,000 \\
\hline Idade (2) & 1,338 & 0,261 & 6,959 & 0,000 & 1,091 & 0,352 & 5,358 & 0,001 \\
\hline Estado Civil (2) & 0,177 & 0,860 & $-1,679$ & 0,094 & $-1,284$ & 0,200 & $-1,572$ & 0,117 \\
\hline Dependentes (1) & 0,139 & 0,890 & 0,845 & 0,398 & $-0,744$ & 0,457 & 0,464 & 0,643 \\
\hline Raça (2) & $-2,872$ & 0,004 & $-0,995$ & 0,320 & $-1,073$ & 0,284 & $-2,075$ & 0,038 \\
\hline Ascendência (2) & 1,103 & 0,354 & 0,267 & 0,899 & 0,868 & 0,483 & 0,594 & 0,667 \\
\hline Ocupação (2) & 5,633 & 0,001 & 3,513 & 0,015 & 2,715 & 0,044 & 7,212 & 0,000 \\
\hline Formação (1) & 2,235 & 0,026 & 9,444 & 0,000 & 2,800 & 0,005 & 8,715 & 0,000 \\
\hline Renda (2) & 3,109 & 0,027 & 5,821 & 0,001 & 0,526 & 0,664 & 6,632 & 0,000 \\
\hline
\end{tabular}

Tabela 2: Valor e Significância do Teste $t$ (1) e da ANOVA (2) para as variáveis demográficas e socioeconômicas

Fonte: Elaborada pelos autores.

No que tange ao conhecimento financeiro, foram encontradas diferenças significativas para as variáveis gênero, idade, ocupação, formação e renda. Verificando o padrão de respostas de homens (média 1,75) e mulheres (média 1,25), observou-se que as mulheres apresentam maior dificuldade em compreender conceitos financeiros e, consequentemente, exibem um menor nível de conhecimento financeiro. O resultado encontrado ratifica a maioria dos estudos que apontam as mulheres como detentoras de menor conhecimento financeiro (Lusardi, Mitchel \& Curto, 2010; Sekita, 2011; Lusardi e Mitchel, 2011). Ao analisar a variável idade, encontrouse no grupo de faixa etária entre 21 e 22 anos (média 1,69) os detentores do maior conhecimento financeiro e no grupo dos indivíduos com menos de 20 anos (média 1,29) os menores valores de conhecimento. No que tange à variável ocupação, verificou-se que os universitários que se intitulam funcionários públicos (média 1,69) e os que possuem a maior faixa de renda (média 1,79) são detentores de níveis maiores de conhecimento financeiro. Esse resultado é condizente com o encontrado por Collins (2012), que observou que pessoas com baixa renda têm menor conhecimento financeiro por não possuírem os recursos financeiros necessários para a realização de oficinas ou cursos de educação financeira. Estudos realizados por Lusardi e Mitchell (2005), Lusardi, Mitchell e Curto (2010), Sekita (2011) e Rooij, Lusardi e Alessie (2011) confirmam que indivíduos com renda mais elevada apresentam melhores níveis de conhecimento financeiro. Quanto à formação, encontra-se uma diferença relevante entre os universitários que possuem formação financeira e os que não a possuem, com médias de 1,75 e 1,19, respectivamente, na escala de conhecimento financeiro, o que indica que existem diferenças expressivas entre esses indivíduos.

Ao analisar a atitude financeira, foram encontradas diferenças significativas apenas para as variáveis ocupação e formação. Os universitários intitulados funcionários públicos (média 4,59) e aqueles que possuem formação financeira (média 4,48) são os que apresentam atitudes financeiras mais favoráveis entre os pesquisados.

Já no que tange à alfabetização financeira, verificou-se a existência de diferenças significativas nas variáveis gênero, idade, raça, ocupação, formação e renda. Os universitários do gênero masculino (média 2,21) demonstraram possuir uma maior alfabetização financeira do que os indivíduos do gênero feminino (média 2,03). Tal resultado mostra-se congruente com o estudo desenvolvido por Lusardi, Mitchel e Curto (2010), os quais verificaram uma grande lacuna de conhecimento financeiro entre homens e mulheres, sendo os homens os maiores detentores desse conhecimento. Outros estudos, como os realizados por Lusardi e Mitchel (2010) e Sekita (2011), ampliam as evidências de que as mulheres apresentam maior embaraço em realizar cálculos financeiros, não detêm o domínio de conceitos financeiros básicos e possuem menor nível de conhecimento, o que acaba por dificultar a tomada de decisões financeiras responsáveis.

Além disso, os universitários que se encontram na faixa etária entre 21 e 22 anos (média 2,17) e que são da raça branca (média 2,12) são os que apresentam maiores índices de alfabetização financeira. No que tange 
à ocupação, os funcionários públicos (média 2,26) e os universitários que não trabalham (média 2,07) são os que demonstram os maiores e piores níveis de alfabetização financeira, respectivamente. Ao analisar a variável renda, verificou-se que os indivíduos com maior poder aquisitivo (média 2,28) são os detentores de maiores índices de alfabetização.

Quanto à formação, foi possível observar que os estudantes de cursos que possuem, em sua grade curricular, disciplinas relativas às Finanças apresentam um maior grau de alfabetização financeira. Tal resultado evidencia a importância da inclusão de disciplinas que abordem questões sobre gestão financeira pessoal e tragam insights sobre conceitos, produtos e práticas financeiras em todos os cursos, independentemente da área a que pertencem, uma vez que a presença de tais disciplinas possibilita aos indivíduos maior acesso a questões econômicas e financeiras e uma melhor compreensão sobre tais questões.

Por fim, com o intuito de verificar a influência das variáveis socioeconômicas e demográficas na variável alfabetização financeira, realizou-se uma análise de regressão linear múltipla, conforme a Equação [2]. Para a estimação do modelo de regressão linear, utilizou-se a estimação por Mínimos Quadrados Ordinários (MQO) e o método Stepwise. O melhor modelo é descrito na Tabela 3.

\begin{tabular}{|c|c|c|c|c|}
\hline \multirow{2}{*}{ Variáveis } & \multirow{2}{*}{ Coeficientes } & \multicolumn{2}{|c|}{ Teste $\mathrm{t}$} & \multirow{2}{*}{ VIF } \\
\hline & & Valor & Sig & \\
\hline Dummy formação & 0,324 & 8,193 & 0,000 & 1,037 \\
\hline Dummy gênero & 0,204 & 5,138 & 0,000 & 1,042 \\
\hline Dummy ocupação & 0,141 & 3,618 & 0,000 & 1,011 \\
\hline Dummy raça & 0,091 & 2,335 & 0,020 & 1,004 \\
\hline
\end{tabular}

Tabela 3: Resultados da regressão múltipla por Mínimos Quadrados Ordinários pelo método Stepwise,
estimada para a alfabetização financeira

Fonte: Elaborada pelos autores.

O resultado apresenta quatro variáveis independentes, com um $\mathbb{R}^{2}$ ajustado de 0,201 , o que significa que as variáveis independentes em conjunto explicam $20,1 \%$ da variável dependente. A significância do teste $\mathrm{F}$ (valor 33,205 e sig. 0,000) indica que pelo menos uma das variáveis independentes exerce influência sobre a variável dependente, sendo considerado o modelo significativo. Quanto aos pressupostos do modelo, observouse que: (i) não há autocorrelação serial, uma vez que o valor do teste de Durbin Watson $(1,829)$ ficou dentro do intervalo considerado adequado $(1,824<\mathrm{d}<2,118)$; (ii) o modelo não apresenta problemas de multicolinearidade, dado que os FIVs ficaram próximos a 1; (iii) os resíduos do modelo possuem distribuição normal, uma vez que o teste Kolmogorov-Smirnov não foi significativo $(0,733$ e sig. 0,656); e (iiii) os resíduos do modelo são homocedásticos, já que o teste Pesarán-Pesarán não rejeitou a hipótese nula de que assim sejam $(0,638$ e sig. 0,425$)$.

Analisando os coeficientes que expressam a magnitude e a direção da relação de cada uma das variáveis independentes sobre a variável dependente, constatou-se que as variáveis gênero, raça, ocupação e formação exercem influência positiva na alfabetização financeira. Esses resultados evidenciam que os indivíduos que são do gênero masculino, se consideram de raça branca, trabalham e possuem formação financeira são os que apresentam maiores níveis de alfabetização financeira.

Visando dar robustez à análise, o modelo proposto inicialmente foi reestimado de duas formas. Inicialmente, substituiu-se a variável dependente alfabetização financeira, que foi mensurada a partir da soma padronizada dos fatores comportamento financeiro, conhecimento financeiro e atitude financeira, por uma abordagem alternativa, mensurando-se esta variável através da análise fatorial exploratória. Conforme exposto na metodologia, a diferença principal reside no fato de que, na estimação inicial, atribuem-se pesos iguais aos fatores, enquanto que, na análise fatorial exploratória, os pesos atribuídos são baseados na carga fatorial. Com isso, obteve-se um único fator composto pelas variáveis comportamento financeiro, conhecimento financeiro e atitude financeira com cargas fatoriais de $0,810,0,451$ e 0,797 , respectivamente. O KMO exibiu um coeficiente de 0,539 e o teste de esfericidade de Bartlett foi significativo (valor 116,521 e sig. 0,000), indicando a fatorabilidade dos dados. Assim, com o intuito de verificar a influência das variáveis socioeconômicas e demográficas no fator alfabetização financeira, novamente, utilizou-se a estimação por Mínimos Quadrados Ordinários (MQO) e o método Stepwise, bem como as mesmas variáveis independentes da regressão inicial. A Tabela 4 apresenta os resultados dessa análise.

\begin{tabular}{l|c|c|c|c}
\multicolumn{1}{c|}{ Variáveis } & \multirow{2}{*}{ Coeficientes } & \multicolumn{2}{|c|}{ Teste t } & \multirow{2}{*}{ VIF } \\
\cline { 3 - 5 } & & Valor & 0,000 & 1,002 \\
\hline Dummy formação & 0,258 & 6,261 & 0,000 & 1,003 \\
\hline Dummy ocupação & 0,163 & 3,956 & 0,006 & 1,004 \\
\hline Dummy raça & 0,114 & 2,766 &
\end{tabular}

Tabela 4: Resultados da regressão múltipla por Mínimos Quadrados Ordinários pelo método Stepwise, estimada para o fator alfabetização financeira

Fonte: Elaborada pelos autores. 
O resultado da regressão reduz o modelo para três variáveis independentes, com um $R^{2}$ ajustado de 10,3\%. As estatísticas do teste F (valor 20,329 e sig. 0,000) e do Durbin Watson (1,837), os valores FIV, o teste Kolmogorov-Smirnov $(0,740$ e sig. 0,644$)$ e o teste Pesarán-Pesarán $(0,534$ e sig. 0,465) indicam a adequação do modelo.

Ao analisar os coeficientes das variáveis independentes, constatou-se que as características possuir formação financeira, ser da raça branca e ter um trabalho formal impactam positivamente os níveis de alfabetização financeira. No entanto, esse modelo explica apenas 10,3\% dessa relação. Utilizando-se a variável alfabetização financeira inicialmente proposta, o coeficiente de determinação aumenta para 20,1\%, o que indica que o modelo anteriormente proposto é mais explicativo.

O segundo método utilizado visando dar robustez à análise, incluiu no primeiro modelo proposto a variável independente renda. No entanto, como alguns indivíduos não declararam renda, a amostra nesse modelo foi reduzida para 353 casos. A Tabela 5 apresenta os resultados da regressão múltipla, com a inclusão da variável renda.

\begin{tabular}{l|c|c|c|c}
\hline \multicolumn{1}{c|}{ Variáveis } & \multirow{2}{*}{ Coeficientes } & \multicolumn{2}{c|}{ Teste t } & \multirow{2}{*}{ VIF } \\
\cline { 3 - 5 } & & Valor & 0,000 & 1,053 \\
\hline Dummy formação & 0,340 & 6,986 & 0,000 & 1,043 \\
\hline Dummy gênero & 0,201 & 4,150 & 0,002 & 1,028 \\
\hline Renda & 0,153 & 3,181 & 0,007 & 1,019 \\
\hline Dummy ocupação & 0,130 & 2,721 & Sig \\
\hline Tabela 5: Resultados da regressão múltipla por Mínimos Quadrados Ordinários pelo método Stepwise
\end{tabular}

Tabela 5: Resultados da regressão múltipla por Mínimos Quadrados Ordinários pelo método Stepwise, estimada para a alfabetização financeira, incluindo a variável renda

Fonte: Elaborada pelos autores.

O modelo apresenta quatro variáveis independentes, com um $\mathbb{R}^{2}$ ajustado de $21,5 \%$. As estatísticas do teste $\mathrm{F}$ (valor 23,867 e sig. 0,000 ) e do Durbin Watson $(1,694)$, os valores FIV, o teste Kolmogorov-Smirnov $(0,582$ e sig. 0,887$)$ e o teste Pesarán-Pesarán $(0,017$ e sig. 0,895) indicam a adequação do modelo.

De forma similar ao primeiro modelo, as variáveis independentes formação, gênero e ocupação exercem uma influência positiva na alfabetização financeira. Além disso, a variável independente incluída - renda - é significativa e tem uma influência positiva. Constata-se, portanto, que, além dos indivíduos do gênero masculino, que trabalham e possuem formação financeira, aqueles que possuem níveis maiores de renda também apresentam maiores níveis de alfabetização financeira. Esse resultado é semelhante ao encontrado por Monticone (2010) que detectou um efeito pequeno, mas positivo da renda sobre a alfabetização financeira na Itália.

Os resultados dos três modelos estimados vão ao encontro das evidências obtidas por Atkinson e Messy (2012), que realizaram um estudo piloto em 14 países sobre alfabetização financeira, através da Organização para Cooperação e Desenvolvimento Econômico (OCDE), e identificaram que os homens são significativamente mais alfabetizados financeiramente que as mulheres em nove países e que não há país onde as mulheres apresentam pontuação significativamente maior que os homens. Além disso, em todos os países, a escolaridade é significativamente relacionada com uma melhor alfabetização financeira.

\section{Conclusões e Recomendações}

Em um primeiro momento, observou-se que os estudantes apresentam um comportamento financeiro positivo, mas não totalmente satisfatório. Em termos mais específicos, verificou-se que os universitários: preocupam-se em bem gerir os recursos, controlar e cumprir os compromissos financeiros assumidos; são cautelosos no uso do cartão de crédito; procuram não comprar por impulso; seguem um orçamento mensal; e estabelecem metas financeiras. O comportamento mais insatisfatório foi demonstrado para o fator investimento e poupança, dado que os estudantes não apresentam, de forma bem estabelecida, hábitos de poupar mensalmente e de manter uma reserva financeira para casos inesperados. O fato de os estudantes não terem bem desenvolvido esse hábito pode ser explicado pelo estágio do ciclo de vida dos mesmos (os jovens não se preocupam tanto em poupar, se comparados a pessoas mais velhas) ou, ainda, pelo seu baixo nível de renda, que não permite a formação de uma reserva. De modo geral, indivíduos do gênero masculino, funcionários públicos, com níveis mais elevados de renda e que possuem formação financeira durante sua graduação apresentam melhores comportamentos na hora de administrar os recursos financeiros.

Quanto ao conhecimento financeiro, observou-se que os universitários pesquisados apresentam dificuldades de entendimento acerca de conceitos e produtos financeiros. Tal resultado é preocupante já que os estudantes não detêm um completo domínio de questões básicas, tais como taxa de juros, inflação e valor do dinheiro no tempo, as quais são pré-requisitos para a realização de transações financeiras do dia a dia. Porém, apresentam um nível de conhecimento em instrumentos financeiros complexos, como ações, títulos públicos, diversificação de investimentos, risco e retorno, superior ao nível encontrado para as questões básicas. Apesar de o conhecimento financeiro como um todo ser baixo, os estudantes do gênero masculino, de cursos que apresentam em sua grade curricular disciplinas de finanças e com maior nível de renda apresentam maior entendimento, se comparados aos demais grupos. 
De forma geral, ao analisar as atitudes financeiras dos indivíduos, percebeu-se que os universitários apresentam atitudes financeiras adequadas, principalmente no que se refere ao controle das despesas pessoais e de seus gastos. Analisando as diferenças entre os grupos, notou-se que os indivíduos que possuem formação financeira apresentam atitudes financeiras mais favoráveis entre os pesquisados.

Por fim, com a formação da variável alfabetização financeira, constatou-se que os estudantes apresentam um nível intermediário de alfabetização, em que os indivíduos do gênero masculino, detentores das maiores faixas de renda e com formação financeira são os que demonstraram os níveis mais elevados. Além disso, a alfabetização financeira é influenciada positivamente pelas variáveis formação, ocupação, gênero e renda, as quais explicam $21,5 \%$ da alfabetização financeira.

Como principal conclusão, constatou-se que os universitários entrevistados não apresentam níveis desejados de alfabetização financeira, dado o comportamento mediano em determinados aspectos de gestão financeira, como a poupança, e, principalmente, os níveis insatisfatórios de conhecimento e compreensão acerca de questões financeiras. Tal conclusão traz implicações ao ratificar a urgência e a necessidade de serem desenvolvidas ações efetivas para minimizar o problema do analfabetismo financeiro. Uma das possíveis medidas a ser tomada refere-se à inclusão de disciplinas de gestão financeira pessoal e de noções de finanças de mercado em todos os cursos de graduação, independente da área de ensino, já vez que foi constatada a influência direta desse fator no nível de alfabetização financeira. Outra medida possível diz respeito ao desenvolvimento e à adoção de programas educativos, os quais devem promover a alfabetização financeira pessoal nas universidades e nos demais setores da sociedade.

Este estudo é um dos pioneiros, em âmbito brasileiro, a avaliar o nível de alfabetização financeira de estudantes universitários e a apresentar evidências de que mesmo os estudantes que possuem formação financeira não apresentam níveis satisfatórios de alfabetização. Estudos futuros podem ampliar esta pesquisa visando outros públicos-alvo, a fim de realizar comparativos entre a população. Além disso, sugere-se o desenvolvimento de pesquisas visando à construção e validação de outros instrumentos para avaliação da alfabetização financeira.

\section{Notas}

1 - Agradecemos aos avaliadores anônimos pelas valiosas contribuições para o aprimoramento deste trabalho.

2- Agradecemos ao Conselho Nacional de Desenvolvimento Científico e Tecnológico (CNPQ) pelo apoio financeiro.

\section{Referências}

Alessie, R., Van Rooij, M., \& Lusardi, A. (2011). Financial literacy and retirement preparation in the Netherlands. Journal of Pension Economics and Finance, 10(04), 527-545. Retrieved Apr 16, 2013, from http://dx.doi.org/10.1017/S1474747211000461

Almenberg, J., \& Save-Soderbergh, J. (2011). Financial literacy and retirement planning in Sweden. Journal of Pension Economics and Finance, 10(04), 585-598. Retrieved Apr 17, 2013, from http://dx.doi.org/10.1017/S1474747211000497

Amadeu, J. R. (2009). A educação financeira e sua influência nas decisões de consumo e investimento: proposta de inserção da disciplina na matriz curricular. Dissertação de Mestrado, Universidade do Oeste Paulista, São Paulo, SP, Brasil. Disponível: http://tede.unoeste.br/tede/tde_arquivos/1/TDE-20110519T144356Z214/Publico/Dissertacao. pdf

Anderloni, L., \& Vandone, D. (2010). Risk of Overindebtedness and behavioral factors. [ Working Paper № 25]. Social Science Research Network, Santa Monica, CA. Retrieved Apr 01, 2013, from http://dx.doi.org/10.2139/ssrn.1653513

Ansong, A. (2011). Level of knowledge in personal finance by university freshmen business students. African Journal of Business Management, 5(22), 8933-8940. Retrieved Apr 16, 2013, from http://www.academicjournals.org/ajbm/pdf/pdf2011/30Sept/Ansong.pdf

Atkinson, A., \& Messy, F. (2012). Measuring Financial Literacy: Results of the OECD / International Network on Financial Education (INFE) Pilot Study [ Working Paper No 15]. OECD Working Papers on Finance, Insurance and Private Pensions, OECD Publishing. Retrieved Apr 05, 2013, from http://dx.doi.org/10.1787/5k9csfs90fr4-en

Avard, S., Manton, E., English, D., \& Walker, J. (2005). The financial knowledge of college freshmen. College Student journal. 39(02), 321-339. Retrieved Apr 15, 2013, from http://law-journals-books.vlex.com/vid/financialknowledge-college-freshmen-62484018

Aviz, C. (2009). Demandas de educação financeira pessoal no ensino médio público e privado do Distrito Federal. Trabalho de Conclusão de Curso, Universidade de Brasília, Brasília, Brasil. Disponível: http://bdm.bce.unb.br/bitstream/10483/771/1/2009_Christo pher\%20Aviz.pdf 
Behrman, J. R., Mitchell, O. S., Soo, C., \& Bravo, D. (2010). Financial Literacy, Schooling, and Wealth Accumulation [ Working Paper № 16452]. National Bureau of Economic Research, Cambridge, MA. Retrieved Apr 17, 2013, from http://www.nber.org/papers/w16452.pdf?new_window=1

Bottazzi, R., Jappelli, T., \& Padula, M. (2011). The portfolio effect of pension reforms: evidence from Italy. Journal of Pension Economics and Finance, 10(01), 75-97. Retrieved Apr 05, 2013, from http://dx.doi.org/10.1017/S147474721000003X

Bucher-Koenen, B., \& Lusardi, A. (2011). Financial literacy and retirement planning in Germany. Journal of Pension Economics and Finance, 10(04), 565-584. Retrieved Apr 06, 2013, from http://dx.doi.org/10.1017/S1474747211000485

Chen, H., \& Volpe, R. P. (1998). An analysis of personal financial literacy among college students. Financial Services Review, 7(02), 107-128. Retrieved Apr 13, 2013, from http://www2.stetson.edu/fsr/abstracts/vol_7_num2_107.pdf

Chen, H., \& Volpe, R. P. (2002). Gender differences in personal financial literacy among college students. Financial Services Review, 11(03), 289-307. Retrieved Apr 13, 2013, from http://www2.stetson.edu/fsr/abstracts/vol_11_num3_p289.pdf

Claudino, L. P., Nunes, M. B., \& Silva, F. C. (2009, agosto). Finanças pessoais: um estudo de caso com servidores públicos. Anais do SEMEAD - Seminários em Administração, São Paulo, SP, Brasil, 12.

Cole, S., Sampson, T., \& Zia, B. (2009). Financial Literacy, Financial Decisions, and the Demand for Financial Services: Evidence from India and Indonesia [ Working Paper № 09-117]. Harvard Business School. Retrieved Apr 06, 2013, from http://www1.worldbank.org/prem/poverty/ie/dime_papers/1107.pdf

Criddle, E. (2006). Financial literacy: Goals and values, not just numbers. Alliance, 34, 4.

Crossan, D., Feslier, D., \& Hurnard, R. (2011). Financial literacy and retirement planning in New Zealand. Journal of Pension Economics and Finance, 10(04), 619-635. Retrieved Apr 16, 2013, from http://dx.doi.org/10.1017/S1474747211000515

Disney, R., \& Gathergood, J. (2011). Financial literacy and indebtedness: new evidence for UK consumers. EconPapers, Discussion Papers, University of Nottingham, Centre for Finance, Credit and Macroeconomics (CFCM). Retrieved Apr 10, 2013, from http://econpapers.repec.org/paper/notnotcfc/11_2f05.htm

Fornero, E., \& Monticone, C. (2011). Financial literacy and pension plan participation in Italy. Journal of Pension Economics and Finance, 10(04), 547-564. Retrieved Apr 16, 2013, from http://dx.doi.org/10.1017/S1474747211000473

Gujarati, D. (2006). Econometria básica (4a ed). Rio de Janeiro: Elsevier.

Grable, J. E., \& Joo, S. H. (2006). Student racial differences in credit card debt and financial behaviors and stress. College Student Journal, 40(02), 400-408. Retrieved Apr 16, 2013, from http://law-journalsbooks.vlex.com/vid/racial-differences-behaviors-stress-63114713

Hair, J. R, Black, W. C., Babin, B. J., Anderson, R. E., \& Tatham, R. L. (2009). Análise multivariada de dados (6a ed.). Porto Alegre: Bookman.

Hastings, J., \& Mitchell, O. S. (2011). Financial Literacy: Implications for Retirement Security and the Financial Marketplace. Oxford, UK: Oxford University Press.

Hung, A. A., Parker, A. M., \& Yoong, J. (2009). Defining and measuring financial literacy [ Working Paper № 708]. Social Science Research Network, Santa Monica, CA: RAND Corporation. Retrieved Apr 01, 2013, from http://papers.ssrn.com/sol3/papers.cfm?abstract_id=1498674

Huston, S. J. (2010). Measuring financial literacy. The Journal of Consumer Affairs, 44(02), 296-316. Retrieved Apr 10, 2013, from http://onlinelibrary.wiley.com/doi/10.1111/j.1745-6606.2010.01170.x/pdf

Falahati, L., \& Paim, L. H. (2012). Experiencing financial problems among university students: an empirical study on the moderating effect of gender. Gender in Management: An International journal, 27(05), 315-330.

Retrieved Apr 16, 2013, from http://dx.doi.org/10.1108/17542411211252633

Finke, M. S., Howe, J. S., \& Huston, S. J. (2011). Old Age and the Decline in Financial Literacy. Social Science Research Network. Retrieved Apr 12, 2013, from http://dx.doi.org/10.2139/ssrn.1948627

Kempson, E. (2011). A Framework for Developing International Financial Literacy Surveys. OECD, Improving Financial Education Efficiency: OECD-Bank of Italy Symposium on Financial Literacy, OECD Publishing. Retrieved Apr 16, 2013, from http://dx.doi.org/10.1787/97892 64108219-4-en

Klapper, L., \& Panos, G. A. (2011). Financial literacy and retirement planning: the Russian case. Journal of Pension Economics and Finance, 10(04), 599-618. Retrieved Apr 01, 2013, from http://dx.doi.org/10.1017/S1474747211000503 
Knoll, M. A. Z., \& Houts, C. R. (2012). The financial knowledge scale: an application of item response theory to the assessment of financial literacy. The Journal of Consumer Affairs, 46(03), 381-410. Retrieved Apr 13, 2013, from http://onlinelibrary.wiley.com/doi/10.1111/j.1745-6606.2012.01241.x/pdf

Lucci, C. R., Zerrenner, S. A., Verrone, M. A. G., \& Santos, S. C. (2006, agosto). A Influência da Educação Financeira nas Decisões de Consumo e Investimento dos Indivíduos. Anais do SEMEAD - Seminários em Administração, São Paulo, SP, Brasil, 09.

Lusardi, A. \& Mitchell, O. S. (2005). Financial literacy and planning: implications for retirement wellbeing. [ Working Paper № 108]. Michigan Retirement Research Center, University of Michigan. Retrieved Apr 26, 2013, from http://deepblue.lib.umich.edu/bitstream/handle/2027.42/49432/wp108.pdf?sequence=1

Lusardi, A., \& Mitchell, O. S. (2011). Financial literacy and retirement planning in the United States. Journal of Pension Economics and Finance, Cambridge University Press, 10(04), 509-525. Retrieved Apr 06, 2013, from http://dx.doi.org/10.1017/S147474721100045X

Lusardi, A., Mitchell, O. S., \& Curto, V. (2010). Financial literacy among the young. The Journal of Consumer Affairs, 44(02), 358-380. Retrieved Apr 02, 2013, from http://onlinelibrary.wiley.com/doi/10.1111/j.17456606.2010.01173.x/pdf

Lusardi, A., \& Tufano, P. (2009). Debt literacy, financial experiences, and overindebtedness. [ Working Paper № 14808]. National Bureau of Economic Research, Cambridge, MA. Retrieved Apr 12, 2013, from http://www.nber.org/papers/w 14808.pdf?new_window =1

Mandell, L. (2007). Financial literacy of high schools students. Handbook of Consumer Finance Research, New York: Springer.

Marcolin, S., \& Abraham, A. (2006, September). Financial literacy research: current literature and future opportunities. International Conference of Contemporary Business. Leura, Faculty of Commerce, Charles Sturt University, Bathurst, N.S.W., 3rd.

Matta, R. C. B. (2007). Oferta e demanda de informação financeira pessoal: o Programa de Educação Financeira do Banco Central do Brasil e os universitários do Distrito Federal. Dissertação de Mestrado, Universidade de Brasília, Brasília, Brasil.

Mccormick, M. H. (2009). The effectiveness of youth financial education: a review of the literature. Journal of Financial Counseling and Planning, 20(01), 70-83. Retrieved Apr 12, 2013, from http://www.afcpe.org/assets/pdf/martha_henn_mccormick.pdf

Moore, D. (2003). Survey of Financial Literacy in Washington State: Knowledge, Behavior, Attitudes, and Experiences. Technical report 03-39, Social and Economic Sciences Research Center, Washington State University. Retrieved Apr 15, 2013, from http://www.sesrc.wsu.edu/sesrcsite/papers/files/dfi-techreport-FINAL216-04.pdfMonticone, C. (2010). How Much Does Wealth Matter in the Acquisition of Financial Literacy? The journal of consumer affairs, 44(02), 403-422. Retrieved Apr 16, 2013, from http://onlinelibrary.wiley.com/doi/10.1111/j.1745-6606.2010.01175.x/pdf

Murphy, D. S., \& Yetmar, S. (2010). Personal financial planning attitudes: a preliminary study of graduate students. Management Research Review, 33(08), 811-817. Retrieved Apr 16, 2013, from http://dx.doi.org/10.1108/01409171011065617

Neidermeyer, A. A., \& Neidermeyer, P. E. (2010). The missing curriculum link: personal financial planning. American Journal of Business Education, 3(04), 79-82. Retrieved Apr 06, 2013, from http://journals.cluteonline.com/index.php/AJBE/article/view/417/406

Norvilits, J. M., \& Maclean, M. G. (2010). The role of parents in college students' financial behaviors and attitudes. Journal of Economic Psychology, 31(01), 55-63. Retrieved Apr 16, 2013, from http://dx.doi.org/10.1016/j.joep.2009.10.003

Organização para a Cooperação Econômica e Desenvolvimento. (2009). Improving financial literacy: analysis of issues and policies. OECD Centre: Paris, France.

Organização para a Cooperação Econômica e Desenvolvimento. (2011). Measuring Financial Literacy: Core Questionnaire in Measuring Financial Literacy, Questionnaire and Guidance Notes for conducting an Internationally Comparable Survey of Financial literacy. OECD Centre: Paris, France.

Remund, D. L. (2010). Financial literacy explicated: the case for a clearer definition in an increasingly complex economy. The Journal of Consumer Affairs, 44(02), 276-295. Retrieved Apr 16, 2013, from http://onlinelibrary.wiley.com/doi/10.1111/j.1745-6606.2010.01169.x/pdf

Research, R. M. (2003). Survey of adult financial literacy in Australia. ANZ Banking Group. Retrieved Apr 16, 2013, from http://www.anz.com/Documents/AU/

Aboutanz/AN_5654_Adult_Fin_Lit_Report_08_Web_Report_full.pdf

Rooij, M. C. J. V., Lusardi, A., \& Alessie, R. J. M. (2011). Financial literacy and retirement planning in the Netherlands. Journal of Economic Psychology, 32(04), 593-608. Retrieved Apr 16, 2013, from http://dx.doi.org/10.1016/j.joep.2011.02.004 
Sekita, S. (2011). Financial literacy and retirement planning in Japan. Journal of Pension Economics and Finance, 10(04), 637-656. Retrieved Apr 04, 2013, from http://dx.doi.org/10.1017/S1474747211000527

Schagen, S. (1997). The Evaluation of NatWest Face 2 Face with Finance, NFER.

Shim, S., Xiao, J. J., Barber, B. L., \& Lyons, A. C. (2009). Pathways to life success: a conceptual model of financial well-being for young adults. Journal of Applied Developmental Psychology, 30(06), 708-723. Retrieved Apr 25, 2013, from http://dx.doi.org/10.1016/j.appdev.2009.02.003

Shim, S., Barber, B. L., Card, N. A., Xiao, J. J., \& Serido, J. (2010). Financial socialization of first-year college students: the roles of parents, work, and education. Journal of Youth and Adolescence, 39(12), 1457-1470. Retrieved Apr 26, 2013, from http://dx.doi.org/10.1007/s10964-009-9432-x

Shockey, S. S. (2002). Low-wealth adults financial literacy. Money management behavior and associates factors, including critical thinking. Tese de Doutorado, Universidade de Utah, Estados Unidos.

Vieira, S. F. A., Bataglia, R. T. M., Sereia, V. J., Ribeiro, M. L., \& Lohmann, G. G. (2009, agosto). Educação financeira e decisões de consumo, investimento e poupança: uma análise dos alunos de uma universidade pública do Paraná. Anais do SEMEAD - Seminários em Administração, São Paulo, SP, Brasil, 12.

Vitt, L. A. (2004). Consumers' financial decisions and the psychology of values. Journal of Financial Service Professionals. Retrieved Apr 16, 2013, from http://www.isfs.org/documents-pdfs/jfsp-vitt-article-11-04.pdf

Xiao, J. J., Tang, C., Serido, J., \& Shim, S. (2011). Antecedents and consequences of risky credit behavior among college students: application and extension of the theory of planned behavior. Journal of Public Policy \& Marketing, 30(02), 239-258. Retrieved Apr 01, 2013, from

http://www.marketingpower.com/aboutama/documents/jppm_forthcoming/antecedents_and_consequences.pdf 
Apêndice 1: Estatística descritiva da escala de comportamento financeiro

\begin{tabular}{|c|c|c|c|c|}
\hline Fatores & Variáveis & Média & Mediana & $\begin{array}{l}\text { Desvio } \\
\text { Padrão }\end{array}$ \\
\hline \multirow{8}{*}{ 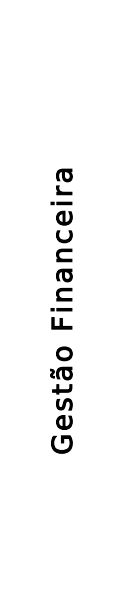 } & 1. Preocupo-me em gerenciar da melhor forma o meu dinheiro. & 4,219 & 4,000 & 0,772 \\
\hline & $\begin{array}{l}\text { 2. Anoto e controlo os meus gastos pessoais (ex.: planilha de } \\
\text { receitas e despesas mensais). }\end{array}$ & 3,206 & 3,000 & 1,340 \\
\hline & $\begin{array}{l}\text { 3. Estabeleço metas financeiras de longo prazo que influenciam na } \\
\text { administração de minhas finanças (ex.: poupar uma quantia " } X \text { " em } \\
1 \text { ano). }\end{array}$ & 3,167 & 3,000 & 1,182 \\
\hline & 4. Sigo um orçamento ou plano de gastos semanal ou mensal. & 3,320 & 3,000 & 1,146 \\
\hline & 5. Fico mais de um mês sem fazer o balanço dos meus gastos. & 3,429 & 4,000 & 1,215 \\
\hline & 6. Estou satisfeito(a) com o sistema de controle de minhas finanças. & 3,424 & 4,000 & 1,105 \\
\hline & 7. Pago minhas contas sem atraso. & 4,422 & 5,000 & 0,900 \\
\hline & Fator Gestão Financeira & 3,598 & 3,571 & 0,730 \\
\hline \multirow{7}{*}{ 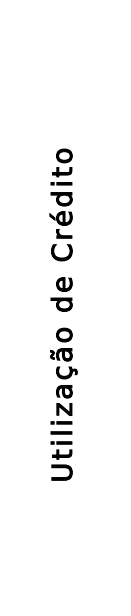 } & $\begin{array}{l}\text { 8. Consigo identificar os custos que pago ao comprar um produto a } \\
\text { crédito. }\end{array}$ & 3,768 & 4,000 & 1,160 \\
\hline & $\begin{array}{l}\text { 9. Tenho utilizado cartões de crédito e cheque especial por não } \\
\text { possuir dinheiro disponível para as despesas. }\end{array}$ & 4,244 & 5,000 & 1,058 \\
\hline & 10. Ao comprar a prazo, comparo as opções de crédito disponíveis. & 3,767 & 4,000 & 1,204 \\
\hline & $\begin{array}{l}\text { 11. Comprometo mais de } 10 \% \text { da minha renda mensal com compras } \\
\text { a crédito (exceto financiamento de imóvel e carro). }\end{array}$ & 3,287 & 3,000 & 1,428 \\
\hline & $\begin{array}{l}\text { 12. Sempre pago o(s) meu(s) cartão(ões) de crédito na data de } \\
\text { vencimento para evitar a cobrança de juros. }\end{array}$ & 4,351 & 5,000 & 0,983 \\
\hline & $\begin{array}{l}\text { 13. Confiro a fatura dos cartões de crédito para averiguar possíveis } \\
\text { erros e cobranças indevidas. }\end{array}$ & 3,576 & 4,000 & 1,498 \\
\hline & Fator Utilização de Crédito & 3,819 & 3,833 & 0,665 \\
\hline \multirow{4}{*}{ 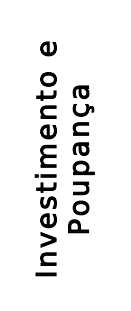 } & 14. Poupo mensalmente. & 3,509 & 4,000 & 1,155 \\
\hline & 15. Poupo visando à compra de um produto mais caro (ex.: carro). & 3,287 & 3,000 & 1,223 \\
\hline & $\begin{array}{l}\text { 16. Possuo uma reserva financeira maior ou igual a } 3 \text { vezes a minha } \\
\text { renda mensal, que possa ser usada em casos inesperados (ex.: } \\
\text { desemprego). }\end{array}$ & 2,679 & 2,000 & 1,534 \\
\hline & Fator Investimento e Poupança & 3,157 & 3,000 & 1,080 \\
\hline \multirow{5}{*}{ 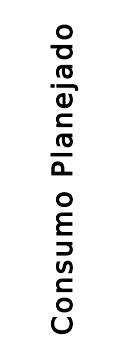 } & 17. Comparo preços ao fazer uma compra. & 4,356 & 5,000 & 0,847 \\
\hline & $\begin{array}{l}\text { 18. Analiso minhas finanças com profundidade antes de fazer } \\
\text { alguma grande compra. }\end{array}$ & 4,225 & 5,000 & 0,995 \\
\hline & 19. Compro por impulso. & 3,679 & 4,000 & 0,926 \\
\hline & $\begin{array}{l}\text { 20. Prefiro comprar um produto financiado a juntar dinheiro para } \\
\text { comprá-lo à vista. }\end{array}$ & 3,725 & 4,000 & 1,097 \\
\hline & Fator Consumo Planejado & 3,994 & 4,000 & 0,635 \\
\hline & Fator Comportamento Financeiro & 3,672 & 3,703 & 0,571 \\
\hline
\end{tabular}

Fonte: Elaborado pelos autores. 
Apêndice 2: Frequência de respostas corretas, incorretas e daquelas referentes às perguntas que os entrevistados não souberam responder e percentual de acertos

\begin{tabular}{|c|c|c|c|c|c|}
\hline Fator & Variáveis & $\begin{array}{l}\text { Respost } \\
\text { a } \\
\text { correta }\end{array}$ & $\begin{array}{l}\text { Respost } \\
\text { a } \\
\text { incorret } \\
\text { a }\end{array}$ & $\begin{array}{l}\text { Não } \\
\text { soube } \\
\text { responde } \\
r\end{array}$ & $\begin{array}{l}\text { Percentual } \\
\text { de acertos } \\
\text { sobre o } \\
\text { total de } \\
\text { respostas }\end{array}$ \\
\hline \multirow{3}{*}{$\begin{array}{l}\text { Conheciment } \\
\text { o financeiro } \\
\text { básico }\end{array}$} & $\begin{array}{l}\text { 21. Suponha que você tenha } \mathrm{R} \$ 100,00 \\
\text { em uma conta poupança a uma taxa de } \\
\text { juros de } 10 \% \text { ao ano. Depois de } 5 \text { anos, } \\
\text { qual o valor que você terá na poupança? }\end{array}$ & 296 & 175 & 62 & $55,50 \%$ \\
\hline & $\begin{array}{l}\text { 22. Imagine que a taxa de juros incidente } \\
\text { sobre sua conta poupança seja de } 6 \% \text { ao } \\
\text { ano e a taxa de inflação seja de } 10 \% \text { ao } \\
\text { ano. Após } 1 \text { ano, o quanto você será } \\
\text { capaz de comprar com o dinheiro dessa } \\
\text { conta? }\end{array}$ & 325 & 37 & 162 & $62,02 \%$ \\
\hline & $\begin{array}{l}\text { 23. Suponha que José herde } \mathrm{R} \$ 10.000,00 \\
\text { hoje e Pedro herde } \mathrm{R} \$ 10.000,00 \text { daqui a } \\
3 \text { anos. Devido à herança, quem ficará } \\
\text { mais rico? }\end{array}$ & 78 & 339 & 106 & $14,91 \%$ \\
\hline \multirow{5}{*}{$\begin{array}{l}\text { Conheciment } \\
\text { o financeiro } \\
\text { avançado }\end{array}$} & $\begin{array}{l}\text { 24. Qual das seguintes afirmações } \\
\text { descreve a principal função do mercado } \\
\text { de ações? }\end{array}$ & 287 & 146 & 92 & $54,67 \%$ \\
\hline & $\begin{array}{l}\text { 25. Considerando-se um longo período de } \\
\text { tempo (ex.: } 10 \text { anos), qual ativo, } \\
\text { normalmente, oferece maior retorno? }\end{array}$ & 167 & 239 & 123 & $31,57 \%$ \\
\hline & $\begin{array}{l}\text { 26. Quanto aos fundos de investimento, } \\
\text { qual das seguintes afirmações está } \\
\text { correta? }\end{array}$ & 157 & 96 & 275 & $29,73 \%$ \\
\hline & $\begin{array}{l}\text { 27. Normalmente, qual ativo apresenta as } \\
\text { maiores oscilações ao longo do tempo? }\end{array}$ & 439 & 21 & 73 & $82,36 \%$ \\
\hline & $\begin{array}{l}\text { 28. Quando um investidor diversifica seu } \\
\text { investimento entre diferentes ativos, } \\
\text { corre o risco de perder dinheiro? }\end{array}$ & 330 & 96 & 104 & $62,26 \%$ \\
\hline
\end{tabular}


Apêndice 3: Estatística descritiva da escala de atitude financeira

\begin{tabular}{|c|c|c|c|}
\hline Variáveis & Média & Mediana & $\begin{array}{l}\text { Desvio } \\
\text { Padrão }\end{array}$ \\
\hline 29. É importante controlar as despesas mensais. & 4,729 & 5,000 & 0,593 \\
\hline 30. É importante estabelecer metas financeiras para o futuro. & 4,583 & 5,000 & 0,657 \\
\hline 31. É importante poupar dinheiro mensalmente. & 4,506 & 5,000 & 0,692 \\
\hline 32. O modo como gerencio o dinheiro hoje irá afetar meu futuro. & 4,229 & 4,000 & 0,893 \\
\hline 33. É importante ter e seguir um plano de gastos mensal. & 4,362 & 4,000 & 0,651 \\
\hline 34. É importante pagar o saldo integral dos cartões de crédito mensalmente. & 4,462 & 5,000 & 0,729 \\
\hline 35. Ao comprar a prazo, é importante comparar as ofertas de crédito disponíveis. & 4,315 & 4,000 & 0,741 \\
\hline 36. É importante não ultrapassar o orçamento do mês. & 4,630 & 5,000 & 0,550 \\
\hline 37. É importante investir regularmente para atingir metas de longo prazo. & 4,153 & 4,000 & 0,731 \\
\hline Fator Atitude Financeira & 4,429 & 4,444 & 0,474 \\
\hline
\end{tabular}

Fonte: Elaborado pelos autores. 